\title{
Contar desde los fragmentos. Rupturas, memoria y lenguaje en dos casos de la historieta argentina contemporánea
}

\section{Vazquez, Laura; Turnes, Pablo}

Resumen:

A partir de las historietas Intrusos, de Dante Ginevra y Diego Agrimbau; y de Menna-Lanzillotto de Matías Trillo, el artículo se propone rastrear formas de re-construir los sentidos de la memoria desde un lenguaje como la historieta desde un contexto histórico presente. El decurso histórico se ve compuesto por fragmentos que construyen tanto un modo de lectura -el historietísticocomo una perspectiva de la construcción de la memoria en relación con el pasado inmediato. En esa reconstrucción, desde la evidencia de los escombros, hay un acto político: el de la lectura/memoria como constante redefinición de aquello que, en principio, aparecería como separado y disperso, pero que al ser re-ensamblado propone una lectura diferente, compartida, cómplice.

\section{Cuadernos del Centro de Estudios de Diseño y Comunicación N74}

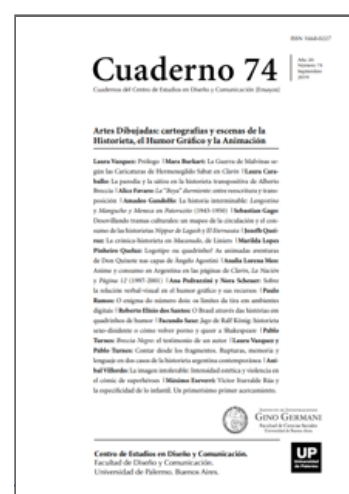

ISSN: 1668-0227

Artes Dibujadas:

cartografías y

escenas de la

Historieta, el Humor

Gráfico y la

Animación

Año XX, Septiembre 2019, Buenos

Aires, Argentina | 256 páginas

descargar PDF

ver índice de la publicación

Ver todos los libros de la publicación

compartir en Facebook

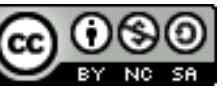

Esta obra está bajo una Licencia Creative

Commons Atribución-NoComercial-

Compartirlgual 4.0 Internacional

Palabras clave: Memoria - Reconstrucción - Fragmentos - Historieta.

$\left(^{*}\right)$ Doctorado y Postdoctorado, Facultad de Ciencias Sociales, UBA. Es investigadora Adjunta del CONICET. En la Carrera de Comunicación de la UBA ha dictado varios seminarios optativos dedicados a la historia y estudio de las artes secuenciales y coordina junto al profesor Oscar Steimberg dirige el Área de Narrativas Dibujadas. Se desempeña como Profesora Asociada en la cátedra Historia de los Medios de Comunicación Nacional y Latinoamericana, en la UNM. Asimismo, es profesora de postgrado en la carrera de Crítica y difusión de las Artes, UNA en donde dicta el Seminario de tesis y el taller de Formatos Mediáticos. Forma parte del Cuerpo Académico del Doctorado en Diseño. Dirige la Línea de Investigación Artes Dibujadas . 
$\left.{ }^{(* *}\right)$ Profesor en Historia por la Universidad Nacional de Mar del Plata; Magíster en Historia del Arte Argentino y Latinoamericano por el Instituto de Altos Estudios Sociales/Universidad Nacional de San Martín; Doctor en Ciencias Sociales por la Universidad de Buenos Aires/CONICET. Jefe de Trabajos Prácticos en la cátedra Historia de los Medios de Comunicación Argentina y Latinoamericana, dirigida por Laura Vazquez, para la Licenciatura en Comunicación Social, Universidad Nacional de Moreno.

En su obra Después del fin del Arte, Arthur Danto afirmaba: “(...) debemos pensar en el arte después del fin del arte, como si estuviéramos en una transición desde la era del arte hacia otra cosa, cuya forma y estructura exacta aún se debe entender" (Danto, 2009, p. 26). El interrogante había dejado de ser qué era o no era arte y ha pasado a ser por qué algo es o no es arte. En ese juego nuevamente abierto se ponían a prueba las técnicas, los lenguajes, las posibilidades artísticas de la producción creativa.

La historieta, cuya lógica funciona bajo otros términos y otra tradición que la del arte, parece estar haciéndose la misma pregunta en esta primera década del siglo XXI. Un buen ejemplo fue la historieta de una sola página titulada Intrusos, del dibujante Dante Ginevra y el guionista Diego Agrimbau (Ver Figura 1). Dicha historieta fue publicada en la revista FIERRO Nro. 36, en octubre de 2009, y suscitó un debate que partió de la pregunta "¿es esto una historieta?” Quisiéramos reformular la pregunta: ¿Por qué considerar esa página una historieta?2

Un signo interesante: la historieta se plantea las mismas preguntas que otros lenguajes y medios se han venido planteado en diferentes momentos, y el deseo de una respuesta transporta a los lenguajes más allá de sus propias fronteras, expandiéndose sobre territorio desconocido. No indagaremos en las posibles definiciones para la historieta, todas ellas son en algún punto fallidas, insuficientes. Son, en todo caso, recortes de corpus culturales aplicados a la historieta. Tomemos, en cambio, la definición del propio guionista respecto a su obra: "Intrusos es una historieta porque lo parece". (Vazquez, 2012)

La historieta de Ginevra/Agrimbau comienza -como suelen hacerlo las obras- con la pregunta ¿cómo contar lo que se quiere contar? Y elige una constricción formal como respuesta: la página única donde contar una secuencia de un solo plano. Es decir, no puede haber secuenciación en el sentido clásico, con los pasajes panel-a-panel, la fragmentación del plano, la elipsis, etc. Esta síntesis radical lejos de promover una solución al esquema lo que hace es potenciar todas aquellas diferencias sublimadas tradicionalmente en el género y la secuenciación. Dibujo y palabras son incrustados sobre el cuadro pero al mismo tiempo mantienen su distancia. Los cartuchos de texto son una serie de epigramas que parecen deslizarse sobre el crepúsculo de las ruinas de un edificio demolido, y simultáneamente parecen abrirse como ventanas al vacío, señalando el artificio. La superficie es la cosa, y entre las grietas el texto afirma su dominio.

Thierry Groensteen nos habla de la solidaridad icónica, la capacidad que las imágenes tienen, desde la puesta en página, de potenciar su inquietante autonomía para reencauzarla en una concatenación de sentidos, constituyéndose como narrativa (Groensteen, 2007, p. 18). Por lo tanto, si se tiene en cuenta que la historieta puede prescindir del texto sin dejar de por eso ser historieta, es la dimensión gráfica la que define todo en su lenguaje. El texto no deja de ser grafía pero, reconoce Groensteen, tampoco un ancla para la mirada: no deja de tener su propio espesor. Deseamos las imágenes congeladas, arrancadas al tiempo en su estética del silencio (Vazquez, 2012, p. 68), pero buscamos el sentido en las palabras. 
Intrusos comprime de tal forma estas unidades irreductibles que hace dibujar a la palabra su camino sobre el dibujo, interviene sobre ese plano gráfico que ya es algo en sí mismo. El texto nos obliga a seguir su espiral descendente, sin poder evitarnos la tentación de desviar la mirada hacia los trazos, los colores, las sombras... ¿Es eso sangre? ¿Son esas las huellas, esos los agujeros las balas? ¿Qué ha pasado/está pasando acá? El texto sigue su camino, imperturbable, para finalmente dibujarnos su pregunta: literalmente un signo de interrogación. Somos devueltos a ese intermedio, al placer del oxímoron.

Creemos que es desde esa figura retórica que conviene pensar a la historieta como lenguaje específico desde una historieta particular -sobre todo si ésta extrema las tensiones que constituyen el lenguaje-. El tiempo narrado corresponde a los fantasmas del pasado que han inscrito su experiencia sobre el presente de los muros derribados. En el cadáver vacío del edificio -el presente del dibujo-, está sepultado el secreto de un crimen. Y aunque sea invisible para los transeúntes, no lo es para el lector a quien se le ofrece una manera de re-leer ese presente desde las huellas exhibidas.

Lo que los autores han hecho es revelar(nos) nuestra propia capacidad para leer historietas, un proceso de desarrollo colectivo, histórico y social. Enfrentados al plano único y fijo, reconstruimos la secuenciación, ordenamos la lectura de derecha a izquierda, recomponemos los espacios entre viñetas utilizando las distancias entre los cuadros de texto y las divisiones estructurales expuestas. Reordenamos lo que en apariencia está desordenado desde una manera de leer asimilada y estandarizada.

Los autores se adelantan a la jugada y entonces, sirviéndose de nuestra fe en el contrato de lectura, somos traicionados y todo vuelve a empezar. Debemos volver sobre nuestro camino para verificar esa solidaridad icónica trasladada a la relación imagen/texto, pero también hacia dentro de la composición del plano. Antes que la arquitectura de un edificio se trata de la arquitectura de la página como puesta-en-página. Desestructurada y desnuda a la vez, está la potencia de su lectura y de sus lectores.

La operación se vuelve doblemente política: es la suma de la elección de una manera de contar más la elección de lo contado. La clave está en un nombre: Garmendia. Es la única palabra que comparten las dos dimensiones del texto textual y del texto diegético. Y ese hilo sutura el sentido pero no lo obtura, lo deja abierto. El edificio revela materialmente la herida sobre la memoria, que aún sangra. Los agujeros de bala y la sangre transforman en fantasmas aquello que está ahora descolorido, sombra de lo que supo estar vivo. Si bien el asesinato de la memoria de una ciudad es metafórico, un punto de fuga se dirige hacia nosotros, testigos silenciosos como los transeúntes de la historieta, que ven perpetrado el crimen cotidiano, acallado y vergonzante.

Cuando yo veía todas esas casas derrumbadas -comenta Agrimbau- no podía evitar pensar que esos restos como las marcas de los muebles o los azulejos rotos que quedan en las demoliciones, eran los restos impresos de una historia pasada. Algo pasó ahí, en ese pasado de la pared. (Vazquez, 2012, p. 72)

La identificación entre ese proceso de destrucción del pasado edilicio y el de la página invierte las imágenes instaladas desde la cotidianidad, quebrando la naturalización de la destrucción de un pasado colectivo. Los mismos autores inscriben sus nombres en un cartel pegado contra la estructura temporal de la obra en construcción. Eventualmente, ellos también serán demolidos, como el cartel con el responsable del crimen. Sin embargo, los roles en la historia no serán los mismos. 
Esto nos devuelve a la pregunta: ¿por qué es una historieta? Hemos visto que cumple con la lógica de la puesta en página, la distribución de los textos sobre el dibujo, el manejo de la disyunción temporal, los recursos retóricos como la metáfora, el texto diegético, la ironía, etc.; incluso propende a la vectorización clásica occidental- de la lectura. Llevando un poco más allá la frase de Agrimbau: Intrusos es una historieta porque nos lo parece, y por lo tanto así la leemos.

Es reafirmación en acto de una memoria subjetiva e históricamente construida, tanto para la forma de lectura -la historieta- como para lo que se lee -el crimen de la destrucción de esa memoria-. He aquí lo político: un lenguaje que se muestra a sí mismo como artificio para contar la destrucción de múltiples relatos sociales y, por lo tanto, trasladar la idea disruptiva que propone que todo relato es, en algún punto, un artificio. Necesario o no, deseable o no, dependerá de la posición que cada lector tome. Ya no hay inocencia posible. Tomemos un segundo ejemplo teniendo en cuenta esta última afirmación. Las dos páginas de Matías Trillo (Ver Figuras 2 y 3 ) son en principio diferentes en objetivo y aproximación gráfico-narrativa. Forman parte del proyecto Historietas por la Identidad, herramienta que las Abuelas de Plaza de Mayo utilizan para su campaña en la búsqueda de aquellos infantes nacidos en cautiverio y posteriormente apropiados por familias que negaron su pasado familiar original3. He aquí una operación interesante que conjuga la necesidad de reconstruir, como en Intrusos, el pasado cancelado por el crimen aún presente. Pero, una vez más ¿cómo hacerlo? Y más específicamente, ¿cómo hacerlo en historieta?

Andreas Huyssen planteó la polémica irresoluble entre el paradigma representativo y el antirepresentativo cuando se trata de abordar el Holocausto - a su vez, paradigma del exterminio sistematizado en su posibilidad real e histórica-. Mientras el primero busca una representación fiel desde la reconstrucción exhaustiva o alegórica, el segundo niega toda posible re-presentación de los hechos bajo el riesgo de banalizar la tragedia. Huyssen vio en Maus, de Art Spiegelman, justamente una salida a esa partida en tablas:

(...) un modo narrativo y de representación figurativa más enajenante para superar los efectos paralizantes de una mímesis de una memoria-terror (...) una estrategia pictórica que mantendría la tensión entre la realidad sobrecogedora de los eventos recordados y el status siempre tenue y elusivo de la memoria misma. (Huyssen, 2000, pp. 73-74)

La estrategia de Trillo consiste en plantear la historieta como un cuento contado a un niño. Ese niño que ya no lo es, obviamente, pero que quedó congelado en su infancia prenatal para el recuerdo de la familia perdida, como los rostros de sus padres en las fotos carnet. De hecho, la figura invisible que interroga se inserta en el centro de la línea donde aparecen las víctimas, sin siquiera tener la sospecha de un rostro.

El rostro dado por la maquinaria estatal -la foto del documento que comprueba que existimos- es, a su vez, prueba de la existencia de un cuerpo desaparecido por esa misma maquinaria cuyo crimen es doble y simultáneo: contra el cuerpo singular y contra el cuerpo social. Las fotografías ingresan a la página de manera disruptiva pero son asimiladas por la lógica de la dimensión gráfica de la historieta. Incluso son retocadas, y se entiende: el tiempo también transforma/deforma los rostros a medida que se alejan de nosotros. O mejor dicho, sólo pueden estar presentes pagando el precio de su transformación en el traslado. En esa primera página, pareciera ser la muerte la que gana la partida. El general, ese avatar del exterminio, ocupa la mitad de la página. El rojo capta rápidamente nuestra atención, nos pone en alerta. El cuadro es de una densidad importante, sus referencias múltiples se disparan por todo el plano: desde las calaveras disparadas por el caño del tanque a 
cuerda -donde puede leerse Proceso de Reorganización Nacional 1976-, manejado por su comandante vampírico que lleva las medallas de los Estados Unidos, la fusión de los colores vaticanos y españoles; y los colores patrios. Detrás de él, la figura que sale del plano luego de haber dado cuerda al tanque, la mano invisibilizada del Mercado que no puede ocultar la sangre en sus zapatos. Como epílogo de fondo, el avión también a cuerda- del exilio. La segunda página redobla la apuesta para volcarla a favor de la memoria, de la vida, de los cuerpos. Entre esa primera mitad, con el diablo y sus verdugos -los engranajes de la maquinaria exterminadora como fondo indican que no hay vacío, sino un sentido específico y deliberado del crimen-; con el asesinados remarcado en rojo, con las manchas salpicando la página y la melancólicas figuras cayendo a su tumba rioplatense; entre toda esa síntesis del horror planificado la página se desgarra y señala al que sigue en lo oscuro esperando ser liberado. Hay ahí un sobreviviente soterrado esperando florecer. Y entonces somos devueltos a un presente que se desea futuro, que ya ha florecido -porque está floreciendo-, donde tenemos los rostros que prueban la continuidad de las vidas canceladas.

El efecto de distanciamiento por la vía infantil responde a la pregunta acerca de "cómo otorgar al pasado una forma visual que se corra de la mera evocación de los hechos" (Vazquez, 2012, p. 118). La voz de un narrador explica formal y cálidamente lo sucedido haciendo efectivo el objetivo de la historieta. El dibujo, sobre el que las palabras parecen deshacerse por momentos -al que esas mismas palabras deben ganarle lugar- sintetiza esa memoria y la proyecta, potenciando sus efectos políticos.

Se trata de una reconstrucción donde las brechas entre paneles no son vacíos a llenar con otras imágenes -ya que el crimen del Estado ha consistido en negarnos esas imágenes posibles- sino que, en términos de Groensteen, nos encontramos con una articulación semántica que resignifica ese vacío dándole un trasfondo particular, históricamente situado, devolviéndoles a los desaparecidos un nombre y un devenir: los MennaLanzillotto (Groensteen, 2007, p. 114).

Al comprender cómo funcionan los casos elegidos, y sumándolos, podemos entenderlos en la perspectiva de la paradoja de Walter Benjamin: mientras que Intrusos es la mirada del ángel que mira un pasado que no es más que una acumulación de ruinas donde las voces de víctimas y victimarios se confunden, Menna-Lanzillotto es el soplo que desde el Edén empuja a la historia hacia lo desconocido del camino, sin poder ignorar la tragedia que ha marcado su trayecto. Pasado y presente se intersectan como lo hacen las palabras y las imágenes, sin poder cancelarse, disparando los sentidos que las originaron.

El gran meta-guión es la historia de un país, y por lo tanto, leer historietas también es leer como un país se ha leído a sí mismo en el tiempo. El crimen, después de todo, es el mismo ¿o acaso sería posible producir silenciosos transeúntes sin el trabajo previo de los verdugos y sus maquinarias? ¿Sería posible derribar el cuerpo urbano, la memoria de las vidas que lo habitaron, sin haber antes destruido los lazos que sostenían el cuerpo de un país? El péndulo parece estar posándose para el mismo lado, aunque los mecanismos que lo hagan funcionar sean diversos -y es bueno que lo sean-.

Una última reflexión: Lucas Berone ha propuesto pensar a la historieta retomando el relato de Benjamin acerca del empobrecimiento de la experiencia derivada del desastre -la guerra, el exterminio, los estigmas del Siglo $X X$-. Es decir, ahí donde la fragmentación impedía a los sujetos reconstruir un relato que pudiera ser transmisible, la historieta ha hecho de los fragmentos pauperizados su lógica (Berone, 2010). Es por eso que es posible pensar este lenguaje propio del siglo XX -junto al cine- como una manera de recuperar la posibilidad de 
relatarnos la tragedia desde la industria cultural, lo cual potencia las posibilidades de llegada -y los riesgos de su banalización- pero que no siempre puede ser reducida a simple mercancía.

El entretenimiento implica el entre-tenernos, el sostenernos mutuamente para hacernos más fuertes (Muñoz y Nine, 2009). Ese entretenimiento ha sido, es cierto, a menudo esquemático y banal. Pero si tenemos en cuenta que es el legado de las esquirlas del pasado, la historieta es siempre un ejercicio en construcción4 . Ha sido necesaria la reproductibilidad infinita para hacernos conscientes de sus posibilidades. Parafraseando a Italo Calvino, la memoria es redundante: repite los signos para que la historieta empiece a existir5.

Notas

1. Una versión de este artículo fue presentado en el panel "Políticas de un lenguaje", dentro de la IX Bienal Iberoamericana de Comunicación, Santiago de Chile, 21 al 23 de agosto de 2013.

2. El debate tuvo lugar en el blog de Hernán Carreas, entre septiembre y octubre de 2009. Enlace directo al artículo en: http://hernancarreras.blogspot.com.ar/2009/09/es-o-no-eshistorieta.html

3. Pueden consultarse las obras realizadas hasta el momento en el sitio oficial: http://hisxi. blogspot.com.ar/

4. Es importante remarcar el hecho que ambas historietas fueron publicadas en la misma revista, que al momento de escritura de este artículo es la única publicación de su tipo que puede considerarse masiva a nivel nacional -exceptuando las ediciones de cómic norteamericano que también son vendidas en los kioscos-. Esto supone, a su vez, la necesidad de revisar los últimos diez años en la historieta y cómo el campo, los autores y los medios han sabido reformular las crisis que supuso la década de 1990 con el final de los dos paradigmas editoriales que sostenían la mayor parte del mercado de historietas: la primera revista FIERRO (1984-1992) y la Editorial Columba -fundada en 1928 y quebrada definitivamente, luego de una prolongada decadencia, en 2001-. Como en otros momentos, las crisis del medio han sabido otorgar oportunidades a autores como Agrimbau y Ginevra para reformular las formas narrativas, luego de su paso por el circuito independiente de fanzines y las experiencias de un hacer post-industrial.

5. La cita original dice: "La memoria es redundante: repite los signos para que la ciudad empiece a existir". Tomado de Italo Calvino, Las Ciudades Invisibles, Buenos Aires, Crisalida Crasis Ediciones, 2008, p. 36. Traducción de Alejandro Benedetti.

Bibliografía

Agrimbau, D. y Varela, L. (2009). Intrusos, en Revista FIERRO Nro. 36, Octubre de 2009, p. 12, Editorial La Página S.A, Buenos Aires.

Berone, L. (2010). “H.G. Oesterheld, narrador de la última experiencia”, en: El hilo de la fábula, Revista anual del Centro de Estudios Comparados, № Diez. Santa Fe, Argentina, edicionesUNL, 2010, pp. 87-98.

Danto, A. C. (2009. 1ed. en inglés de 1997). Después del fin del arte. El arte contemporáneo y el linde de la historia. Traducción de Elena Neerman. Buenos Aires: Paidós. 
Groensteen, T. (2007. 1ed. en francés de 1999). The system of comics. Traducción de Bart Beaty y Nick Nguyen. Mississippi: University Press of Mississippi.

Huyssen, A. (2000). "Of Mice and Mimesis: Reading Spiegelman with Adorno", en New German Critique, No. 81, Dialectic of Enlightenment. (Otoño de 2000), New German Critique, Department of German Studies, Cornell University, New York.

Muñoz, J. (2009). Entrevista realizada por Lucas Nine, Revista Sacapuntas Nro. 20, junio de 2009, publicación digital mensual de la Asociación de Dibujantes de Argentina (ADA). Versión digital: http://asoc-dibujantesarg.wixsite.com/copia-de-a-d-a/sacapuntas

Trillo, M. (2011). Menna-Lanzillotta, en Revista FIERRO Nro. 55, Mayo de 2011, p. 34. Buenos Aires: Editorial La Página S.A.

Vazquez, L. (2012). "Esto no es una historieta” y "Viñetas y nunca más" en Fuera de Cuadro. Ideas sobre historieta, Agua Negra, Buenos Aires, pp. 71-75 y pp. 117-119 respectivamente.

Abstract: With Intruders by Dante Ginevra and Diego Agrimbau; and Menna-Lanzillotto by Matías Trillo, this article proposes ways of re-tracing the way to build memory from the comics language within the current historical context. The historic course is composed of fragments that build both a way of reading -comics- as an insight into the construction of memory in relation to the immediate past. In this reconstruction, made up from the evidence present in history's debris, there is a political act: the reading / memory as a constant redefinition of what, in principle, appear as separate and disperse, but when reassembled, it proposes a different, shared, complicit reading.

Key words: Memory - Reconstruction - Fragments - Comics.

Resumo: Da banda desenhada Intrusos, de Dante Ginevra e Diego Agrimbau; e de Menna- -Lanzillotto por Matías Trillo, o artigo pretende traçar formas de reconstruir os sentidos da memória a partir de uma linguagem, como quadrinhos de um contexto histórico presente. O curso histórico é composto de fragmentos que constroem um modo de leitura - o histórico - como uma perspectiva da construção da memória em relação ao passado imediato. Nesta reconstrução, a partir da evidência dos escombros, há um ato político: o da leitura / memória como uma redefinição constante do que, em princípio, apareceria como separado e disperso, mas quando remontado propõe uma leitura diferente, compartilhado, cúmplice.

Palavras chave: Memória - Reconstrução - Fragmentos - Historieta.

[Las traducciones de los abstracts al inglés y portugués fueron supervisadas por el autor de cada artículo]

Contar desde los fragmentos. Rupturas, memoria y lenguaje en dos casos de la historieta argentina contemporánea fue publicado de la página 191 a página198 en Cuadernos del Centro de Estudios de Diseño y 